\title{
Continuous quality improvement in orthopedic surgery: changes and implications with health system funding reform
}

This guest editorial on quality control measures in orthopedic surgery was invited, as the time has come where we need to look at better quality improvement measures that are meaningful and physician-based. We do not want to have measures imposed that we have had no hand in designing or approving. All surgical specialties - not just orthopedic surgery - will need to be involved in this effort.

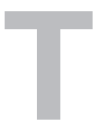

otal health expenditure was expected to reach $\$ 219.1$ billion or $\$ 6105$ per Canadian in $2015,{ }^{1}$ with orthopedic care accounting for approximately $12 \%$ of total hospital acute care costs. ${ }^{2}$ In 2012-13, providing health care in Ontario consumed 42 cents of every tax dollar. Without modification, health spending would account for up to 70 per cent of the provincial budget by $2025 .^{3}$

In an effort to stem the tide, health system funding reform (HSFR) was implemented in April 2012 as part of Ontario's Action Plan for Health Care. A major constituent was the introduction of standardized bundled payments for quality-based procedures (QBP), which serve to reward care that improves patient outcomes. The United States and other countries are also moving toward bundled pricing. ${ }^{4,5}$ Of the QBPs currently in place in Ontario, 20\% (4 of 20) involve orthopedic surgical procedures. ${ }^{6}$

The principle behind HSFR, and the ethos for establishing mandated QBPs, is to improve the quality of health care. The adage goes, "improve the quality of care, enhance patient satisfaction, and thereby improve patient outcomes and lower costs." However, what is quality improvement, and how is it best enacted and then measured?

\section{Quality: What does it mean in today's health care landscape?}

According to the Institute of Medicine, ${ }^{7}$ quality health care should be safe, effective, patient-centred, timely, efficient and equitable. Quality does not necessarily improve by spending more money; quality could be a means to save money, as better coordinated care can lead to lower complication rates, shorter lengths of stay, reduced readmissions, and reduced use of health services after surgery. ${ }^{8}$ Quality of care can be assessed and improved through 3 sequential and interrelated dimensions: structures, processes and outcomes. ${ }^{9}$

Increasingly, data collected through local data sets are being contributed to provincial and national registries in order to help quality-improvement initiatives. ${ }^{10,11}$ The American College of Surgeons' National Surgical Quality Improvement Program (NSQIP) measures and compares the quality of surgical care across North America to enhance a hospital's ability to zero in on preventable complications. ${ }^{12-16}$ As health care is always evolving with advances in technology, procedures and medical knowledge, the need for a "plan, do, study, act" (PDSA) cycle is necessary whereby data can be analyzed instantly and feedback provided constantly in order to continuously revise and improve. ${ }^{16}$

The PDSA cycle forms the basis for continuous quality improvement (CQI), which encompasses processes associated with providing a product or service to meet or exceed customer expectations. The key to any CQI initiative is using a structured planning approach to evaluate current health care structures and processes and improve upon them to achieve the desired outcome and vision. ${ }^{17,18}$ To study and improve structures and processes, time-driven activity-based costing (TDABC) is becoming more frequently used in health care, including orthopedic surgery. ${ }^{19}$

\section{$\mathrm{CQI}$ and orthopedic surgery}

Core aspects of most CQI programs include collection of data that allow assessment of health care structures, processes and patient-centred outcomes; feedback of performance and outcomes data to surgeons and stakeholders, ideally with risk adjustment and benchmarking of the data; and implementation of appropriate interventions to promote reduction in wasteful and inefficient variation in care while simultaneously improving performance. ${ }^{20}$

Despite their relative infancy in health care, CQI programs have proven valuable at improving patient outcomes in orthopedic surgery, one of which was spearheaded by the Alberta Bone and Joint Health Institute..$^{21,22}$ There have also been examples in subspecialties of orthopedic surgery looking at various quality end points, including fall prevention, ${ }^{23}$ antibiotic delivery in the emergency department $^{24}$ and use of stat MRI for acute spine injuries. ${ }^{25}$

Quality improvement plans in Ontario are now a formal commitment aligned with system and provincial priorities. ${ }^{24}$ Surgeons must become active participants in the quality movement by understanding the basic principles of CQI and how they apply to patient care. ${ }^{25}$ Only through 
collaboration and integration can health care incorporate a culture for improving quality and patient safety. Truly improving performance is difficult, though, owing to questions about quality, design care processes, measure inputs and outputs, multistakeholder collaborations, and incentive programs. Major obstacles commonly reported are lack of time, limited resources, lack of training, and pressures to deal with other changes ${ }^{26-29}$ Future efforts in developing quality improvement require strong physician leadership in helping to develop an optimal care team that is as patientcentred as possible. ${ }^{8}$

In summary, CQI programs evaluating health care services can inform choices to optimize care and improve efficiencies through knowledge translation. Successful end products may include better patient satisfaction, improved patient-reported outcomes, highly efficient care pathways, and overall cost savings.

\section{Paul E. Beaulé, MD; Darren M. Roffey, PhD; Stéphane Poitras, PT, PhD}

Affiliations: From the Division of Orthopaedic Surgery, The Ottawa Hospital, Ottawa, Ont. (Beaulé); the Clinical Epidemiology Program, Ottawa Hospital Research Institute, Ottawa, Ont. (Roffey); and the Physiotherapy Program, Faculty of Health Sciences, University of Ottawa, Ottawa, Ont. (Poitras).

Competing interests: None declared.

DOI: $10.1503 /$ cjs. 005416

\section{References}

1. Canadian Institute for Health Information. National health expenditure trends, 1975 to 2015. 2015. Available: www.cihi.ca/sites/default /files/document/nhex_trends_narrative_report_2015_en.pdf (accessed 2016 May 11).

2. Waddell J. Ontario's experience with orthopaedic quality-based procedures and indicators. In: Advancing high-value practices for orthopaedic care. 2015 May 11. Toronto, Ont.

3. Ontario Ministry of Health and Long Term Care. Health system funding reform (HSFR). 2015. Available: www.health.gov.on.ca/en /pro/programs/ecfa/funding/hs_funding.aspx (accessed 2016 May 11).

4. Bozic KJ, Ward L, Vail TP, et al. Bundled payments in total joint arthroplasty: targeting opportunities for quality improvement and cost reduction. Clin Orthop Relat Res 2014;472:188-93.

5. Chernew ME. Why physicians should like bundled payment. Health Serv Res 2011:46:1693-7.

6. Ontario Ministry of Health and Long Term Care. Quality-based procedures. 2015. Available: www.health.gov.on.ca/en/pro/programs /ecfa/funding/hs_funding_qbp.aspx (accessed 2016 May 11).

7. Committee on Quality of Health Care in America. Crossing the quality chasm: a new bealth system for the 21st century. Institute of Medicine, Ed. Washington, DC: National Academy Press; 2001.

8. Saleh KJ, Bozic KJ, Graham DB, et al. Quality in orthopaedic surgery - an international perspective: AOA critical issues. 7 Bone foint Surg Am 2013;95:e3.

9. Donabedian A. Evaluating the quality of medical care. 1966. Milbank Q 2005;83:691-729.

10. Health Quality Ontario. What is quality improvement? 2016. Available: www.hqontario.ca/Quality-Improvement (accessed 2016 May 11).

11. Ontario Ministry of Health and Long Term Care. Quality improvement plans. 2016. Available: www.health.gov.on.ca/en/pro/programs /ecfa/legislation/quality_improve.aspx (accessed 2016 May 11).
12. Montroy J, Breau RH, Cnossen S, et al. Change in adverse events after enrollment in the National Surgical Quality Improvement Program: a systematic review and meta-analysis. PLoS One 2016;26:e0146254.

13. Aoude AA, Aldebeyan SA, Nooh A, et al. Thirty-day complications of conventional and computer-assisted total knee and total hip arthroplasty: analysis of 103,855 patients in the American College of Surgeons National Surgical Quality Improvement Program database. 7 Arthroplasty 2016; doi: 10.1016.

14. Whiting PS, White-Dzuro GA, Avilucea FR, et al. Body mass index predicts perioperative complications following orthopaedic trauma surgery: an ACS-NSQIP analysis. Eur 7 Trauma Emerg Surg 2016; e-pub ahead of print.

15. Drager J, Hart A, Khalil JA, et al. Shorter hospital stay and lower 30-day readmission after unicondylar knee arthroplasty compared to total knee arthroplasty. 7 Arthroplasty 2016;31:356-61.

16. Su AW, Habermann EB, Thomsen KM, et al. Risk factors for 30-day unplanned readmission and major perioperative complications following spine fusion surgery in adults: a review of the National Surgical Quality Improvement Program (NSQIP) database. Spine 2016; e-pub ahead of print.

17. Goldstone J. The role of quality assurance versus continuous quality improvement. 7 Vasc Surg 1998;28:378-80.

18. Health Information Technology Research Center (HITRC). Continuous quality improvement (CQI) strategies to optimize your practice 2013. Available: www.healthit.gov/sites/default/files/tools/nlc _continuousqualityimprovementprimer.pdf (accessed 2016 May 11).

19. Akhavan S, Ward L, Bozic KJ. Time-driven activity-based costing more accurately reflects costs in arthroplasty surgery. Clin Orthop Relat Res 2016;474:8-15.

20. Brindis RG, Dehmer GJ. Continuous quality improvement in the cardiac catheterization laboratory: Are the benefits worth the cost and effort? Circulation 2006;113:767-70.

21. Frank C, Marshall D, Faris P, et al. Joint health I. Essay for the CIHR/CMAJ award: improving access to hip and knee replacement and its quality by adopting a new model of care in Alberta. CMAf 2011;183:E347-50.

22. Marshall DA, Christiansen T, Smith C, et al. Continuous quality improvement program for hip and knee replacement. Am 7 Med Qual 2015;30:425-31.

23. Lohse GR, Leopold SS, Theiler S, et al. Systems-based safety intervention: reducing falls with injury and total falls on an orthopaedic ward. F Bone foint Surg Am 2012;94:1217-22.

24. Collinge CA, McWilliam-Ross K, Kelly KC, et al. Substantial improvement in prophylactic antibiotic administration for open fracture patients: results of a performance improvement program. 7 Orthop Trauma 2014;28:620-5.

25. Potigailo VL, Christoforidis GA, Katzman GL. Acute spinal cord compression: CQI framework increases resource efficiency while promoting delivery of high-quality care. 7 Am Coll Radiol 2015;12:90-4.

26. Ontario HQ. Quality improvement planning. 2016. Available: www .hqontario.ca/Quality-Improvement/Quality-Improvement-Plans (accessed 2016 May 11).

27. Bosco JA, Sachdev R, Shapiro LA, et al. Measuring quality in orthopaedic surgery: the use of metrics in quality management. Instr Course Lect 2014;63:473-85.

28. Baker GR, Barnsley J, Murray M. Continuous quality improvement in Canadian health care organizations. Leadersh Health Serv 1993;2:18-23.

29. Koenig KM, Bozic KJ. Orthopaedic healthcare worldwide: the role of standardization in improving outcomes. Clin Orthop Relat Res 2015;473:3360-3.

30. Wei DH, Hawker GA, Jevsevar DS, et al. Improving value in musculoskeletal care delivery: AOA critical issues. 7 Bone foint Surg Am 2015;97:769-74.

31. Hailer NP. Orthopedic registry research - limitations and future perspectives. Acta Orthop 2015;86:1-2. 